\title{
Research on the Coupling Relationship between the Attributes and the Independence Trend of Secured Interest and Based on Multivariate Linear Regression Equation
}

\author{
Liangsha Gu \\ Oxbridge College, Kunming University of Science and Technology, Kunming, China \\ guliangsha@126.com
}

Keywords: ultiple regression; Mathematical modeling; Coupling relationship; Random variables; Matrix form

\begin{abstract}
. companied by the development of the socialist market economy, the usufructuary rights which corresponds to the secured interest is achieved by people as for the tool of ensuring the the creditor's rights. It has a crucial role in the maintenance of the socialist commodity circulation order and it ensures the legitimate rights and interests of the masses of the people in many areas. This paper first analyzes the secured interest at home and abroad, using the methods of mathematical modeling of the dependency of real rights to do secured multiple regression analysis, deepening the property and independent development trends of further secured interest in China on the basis of it, eventually it concludes that the secured interest has a very important influence on the fulfillment of the protection of debt from the property, independence represents a trend for the future development of the secured interest.
\end{abstract}

\section{Introduction}

Society has paid more and more attention on the maintenance of the socialist commodity circulation, and the protection of the legitimate rights and interests of citizens, legal persons .With the development of China's socialist market economy, the economic ties between the citizens and legal persons in the form of debt become more and more frequently[1]. The debt of the contract and the guarantee are the inevitable outcome of the commodity economy under the high speed development. Only solid economic base can protect the solid growth of the superstructure. The development of the secured interest's properties and independence, which is the driving force of the flow of goods and economic transactions, is also an important guarantee of the rapid improvement and development at the same time.

\section{The independent cognition and the property of the secured interest}

A. The analysis on the property of the secured interest

Secured interest, which is the property rights corresponding with usufructuary, it claims that it is set to ensure the realization of claims, whose content rights is to get the particular property which is obtained directly or it proposes the exchange value of the specific property. Secured interest has been able to guarantee the exercise of creditor's rights, maintain the security of transactions, several important characteristics are shown below.

B. The independent analysis on the secured interest

Independence of the secured interest is that a secured interest exists which is separate from the secured claims. It is referred as an independent guarantee contract of maintenance of creditor exercise, it is able to make a security interest become a single setting, which can be carried out for a number of different claims guarantee, so that the parties can eliminate the trouble which is set as a secured interest one by one. The secured interest aims to the protection of property rights with a high degree of liquidity. Secured interest presents a property of abstract after it is out of the original secured claims, while the existence of such abstract way can make the secured interest no longer eliminate with the principal debt and eradication, which becomes the formation of a secured interest in the optimization form . 


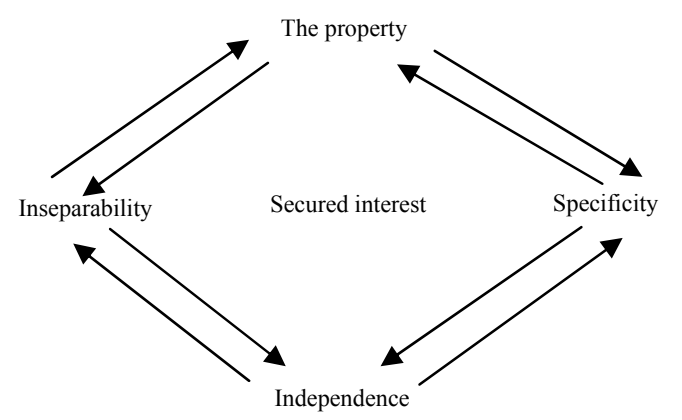

Figure 1. Characteristics of the secured interest

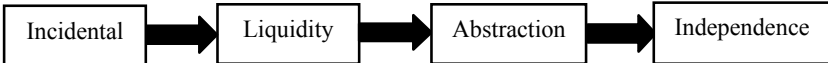

Figure 2. The process of the optimization of secured interest morphogenesis

With the value of property rights increasing, secured interest becomes an independent protection of property rights, having independent exchange value. And it exits in the free flow of economic transactions or debt transactions, it is referred as a value of the right, the independence development of it is indisputable.

\section{The property and the development trend of independence on secured interest in the development of China}

Analysis on the property trends of secured interest

With the development of China 's market economy and debt transactions, the development of forecast claims is becoming more and more important to fulfill the important characteristics of the secured interest in the property of security debt.Thus, it is also indispensable of the analysis and research of a secured interest in the property trends. Set $y$ as an observable random variables here, it is affected by $p$ which has a kind of non - random factors: $x_{1}, x_{2}, \ldots, x_{\mathrm{p}}$ and random factors are $\varepsilon, y$ and $x_{1}, x_{2} \ldots, x_{\mathrm{p}}$ have a linear relationship as follows :

$$
y=\beta_{0}+\beta_{1} x_{1}+\cdots+\beta_{p} x_{p}+\varepsilon
$$

$\beta_{0}, \beta_{1}, \ldots, \beta_{p}$ are $p+1$ unknown parameters , $\varepsilon$ is an unpredictable random error, and it is usually assumed.We call Formula (1) as the multiple linear regression model, we call $y$ as the explanatory variability( the dependent variability ), $x_{i}(i=1,2, \cdots, p)$ is referred as explanatory variables (independent variables ).

$$
E(y)=\beta_{0}+\beta_{1} x_{1}+\cdots+\beta_{p} x_{p}
$$

The theory is the regression equation.

For the trend of the developing problems, multiple regression equation is needed to establish, we must first estimate the unknown parameters $\beta_{0}, \beta_{1}, \ldots, \beta_{p}$, we have to do $n$ times independent observations and obtain $n$ groups of sample data $\left(x_{i 1}, x_{i 2}, \cdots, x_{i p} ; y_{i}\right), i=1,2, \cdots, n$, they satisfy the equation ( 1 ), namely:

$$
\left\{\begin{array}{c}
y_{1}=\beta_{0}+\beta_{1} x_{11}+\beta_{2} x_{12}+\cdots+\beta_{p} x_{1 p}+\varepsilon_{1} \\
y_{2}=\beta_{0}+\beta_{1} x_{21}+\beta_{2} x_{22}+\cdots+\beta_{p} x_{2 p}+\varepsilon_{2} \\
\quad \cdots \cdots \cdots \\
y_{n}=\beta_{0}+\beta_{1} x_{n 1}+\beta_{2} x_{n 2}+\cdots+\beta_{p} x_{n p}+\varepsilon_{n}
\end{array}\right.
$$

$\varepsilon_{1}, \varepsilon_{2}, \cdots, \varepsilon_{n}$,which is independent with each other and it has to obey $N\left(0, \sigma^{2}\right)$

The formula (3) can be expressed in a matrix form :

$$
Y=X \beta+\varepsilon
$$

Under the debt transactions, the establishment and existence of the guarantee must be the premise of a certain creditor relations, it is a legal relationship which subordinates with creditor relations, it 
can not be alone that is separated from the general and secured claims. From the aspect of claims , from the side of the debt, the guarantee is the obligation .

Here, $Y=\left(y_{1}, y_{2}, \cdots, y_{n}\right)^{T} \beta=\left(\beta_{0}, \beta_{1}, \cdots, \beta_{p}\right)^{T} \varepsilon=\left(\varepsilon_{1}, \varepsilon_{2}, \cdots, \varepsilon_{n}\right)^{T} \varepsilon \sim N_{n}\left(0, \sigma^{2} I_{n}\right) I_{n}$ is the $n$ unit matrix .

$$
X=\left[\begin{array}{ccccc}
1 & x_{11} & x_{12} & \cdots & x_{1 p} \\
1 & x_{21} & x_{22} & \cdots & x_{2 p} \\
\vdots & \vdots & \vdots & & \vdots \\
1 & x_{n 1} & x_{n 2} & \cdots & x_{n p}
\end{array}\right]
$$

$n \times(p+1)$ order matrix call $X$ as a data matrix or design matrix, and assuming that it is a full column $\operatorname{rank}$, namely $\operatorname{rank}(X)=p+1$

Seen from the model (3) as well as the nature of the multivariate normal distribution, the property $Y$ still obey $n$ dimensional normal distribution, its expectation vector is $X \beta$. Variance and covariance matrix are $\sigma^{2} I_{n}$. That is $Y \sim N_{n}\left(X \beta, \sigma^{2} I_{n}\right)$.Extension of the multiple linear regression model is confirmed that the secured interest in recent years has been lessened from the property development and its development trend marks the development of China 's secured interest which will be a new goal and direction in the future.

Analysis on the independent development trend of secured interest

From the point of view of the legislative and judicial pragmatic in the world, they basically break through the restrictions from the properties of the secured interest; From the realistic level, the development trend of the world 's secured interest goes forward to independence .In our country, in order to make the secured interest liquid, it is necessary to develop the secured interest.According to a multiple linear regression equation, it has unknown parameters $\beta_{0}, \beta_{1}, \cdots, \beta_{p}$, and it analyzes the trends of the independence of modern China 's secured interest, that we choose $\beta=\left(\beta_{0}, \beta_{1}, \cdots, \beta_{p}\right)^{T}$ as making the sum of squared errors and achieving the minimum[2]:

$$
\begin{aligned}
Q(\beta) & \triangleq \sum_{i=1}^{n} \varepsilon_{i}^{2}=\vec{\varepsilon}^{T} \vec{\varepsilon}=(Y-X \beta)^{T}(Y-X \beta) \\
& =\sum_{i=1}^{n}\left(y_{i}-\beta_{0}-\beta_{1} x_{i 1}-\beta_{2} x_{i 2}-\cdots-\beta_{p} x_{i p}\right)^{2}
\end{aligned}
$$

For $Q(\beta)$ is about $\beta_{0}, \beta_{1}, \cdots, \beta_{p}$, which is a non- negative quadratic function, and thus there must be a minimum, the usage of the calculus Extreme Value[3]:

$$
\left\{\begin{array}{c}
\frac{\partial Q(\hat{\beta})}{\partial \beta_{0}}=-2 \sum_{i=1}^{n}\left(y_{i}-\hat{\beta}_{0}-\hat{\beta}_{1} x_{i 1}-\hat{\beta}_{2} x_{i 2}-\cdots-\hat{\beta}_{p} x_{i p}\right)=0 \\
\frac{\partial Q(\hat{\beta})}{\partial \beta_{1}}=-2 \sum_{i=1}^{n}\left(y_{i}-\hat{\beta}_{0}-\hat{\beta}_{1} x_{i 1}-\hat{\beta}_{2} x_{i 2}-\cdots-\hat{\beta}_{p} x_{i p}\right) x_{i 1}=0 \\
\ldots \ldots \ldots \ldots \ldots \ldots \\
\frac{\partial Q(\hat{\beta})}{\partial \beta_{k}}=-2 \sum_{i=1}^{n}\left(y_{i}-\hat{\beta}_{0}-\hat{\beta}_{1} x_{i 1}-\hat{\beta}_{2} x_{i 2}-\cdots-\hat{\beta}_{p} x_{i p}\right) x_{i k}=0 \\
\quad \ldots \ldots \ldots \ldots \ldots . . \\
\frac{\partial Q(\hat{\beta})}{\partial \beta_{p}}=-2 \sum_{i=1}^{n}\left(y_{i}-\hat{\beta}_{0}-\hat{\beta}_{1} x_{i 1}-\hat{\beta}_{2} x_{i 2}-\cdots-\hat{\beta}_{p} x_{i p}\right) x_{i p}=0
\end{array}\right.
$$

It is not difficult to find the results from the above derivation, with the development of the commodity economy and credit relations, the secured interest in the independence shows its advantages on the exercise of the security claims gradually, it is beneficial to many collateral form which becomes a synergy and it has mutual support in the claims, it avoids and resolves risks on the debt of the transactions and capital flows. Here, $\hat{\beta}_{i}(i=0,1, \cdots, p)$ is $\hat{\beta}_{i}(i=0,1, \cdots, p)$ least squares estimation, it can be used for the partial derivative $Q(\beta)$, it obtains formal equations matrix algebraic operations, the matrix of the normal equations[4] :

$$
X^{T}(Y-X \hat{\beta})=0
$$

The transposition of formula (8) is[5]:

$$
X^{T} X \hat{\beta}=X^{T} Y
$$

The equations (9) is the normal equations. 
According to the hypothesis $R(X)=p+1$, So $R\left(X^{T} X\right)=R(X)=p+1$. Therefore $\left(X^{T} X\right)^{-1}$. Solution of normal equations (5) is[6]:

$$
\hat{\beta}=\left(X^{T} X\right)^{-1} X^{T} Y
$$

We can get the empirical regression equation as the following formula[7]:

$$
\hat{y}=\hat{\beta}_{0}+\hat{\beta}_{1} x_{1}+\hat{\beta}_{2} x_{2}+\cdots+\hat{\beta}_{p} x_{p} \quad(11)
$$

Regression equation which is based on the above experience, it estimates independence trends of deriving from the error variance $\sigma^{2}$.Each set of observed values of the independent variable which is substituted into the regression equation, the estimated amount of the dependent variable (fitted value)[8]:

$$
\hat{Y}=\left(\hat{y}_{1}, \hat{y}_{2}, \cdots, \hat{y}_{p}\right)^{2}=X \hat{\beta} \quad(1 \quad)
$$

According to the derivation and analysis of the independence of the secured interest, it is a trend of rapid development trend in China 's commodity economy development , and it protects debt transactions of the property rights of citizens and legal persons .

\section{Analysis on the significance of the properties which is related to the secured interest on the protection of the debt performance}

Along with the business of commodity producers and operators that has the need for capital and bank credit, it is widely expanded to make the secured interest recognized, the development of the secured interest has finally broken through the traditional theory, it begins to develop into the independence. In the traditional theory, the security interest has always maintained the claims of subordinate and main characteristics, it is accompanied by the establishment and disappearance of the principal debt, accompanying the properties of the principal debt in debt transactions, protecting the traders' property rights in capital flows and debt transactions against infringement .

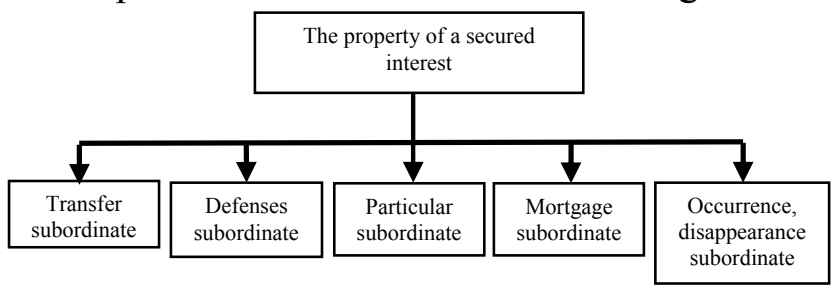

Figure 3. The property content of security interest

To analyze the importance of the secured interest in the protection of the principal debt from the property, the secured interest is from the property argument $x_{1} x_{2} \ldots, x_{\mathrm{p}}$. On the whole, the random variable $y$ is tested whether there is a significant effect, that is the hypothesis[9] :

$$
\left\{\begin{array}{l}
H_{0}: \beta_{1}=\beta_{2}=\cdots=\beta_{p}=0 \\
H_{1}: \beta_{i} \neq 0,1 \leq i \leq p
\end{array}\right.
$$

If attribute $H_{0}$ is accepted, $y$ is not indicated with $x_{1} . . x_{2} ., x_{p}$, the linear relationship does not exist, in order to illustrate how the research is tested, the establishment of the analysis of variance table is used to observe value, that is $y_{1} . . y_{2} . y_{n}$, the reason why there are differences is that the following two reasons exiting, on one hand, $y$ has a linear relationship with $x_{1}, x_{2}, x_{\mathrm{p}}$, because of the different values which is caused by the change of the value $y_{i}(i=1,2, \ldots, n)$; on the other hand, that $y$ is removed and the factors of $x_{1}, x_{2}, \ldots, x_{\mathrm{p}}$ does not have the linear relationship with it other than other factors. For example, the influence of $x_{1}, x_{2}, \ldots, x_{\mathrm{p}}$ towards non-linear effects of $y$ and random factors. The data is $\bar{y}=\frac{1}{n} \sum_{i=1}^{n} y_{i}$, so the total sum of squares is (Total the Sum of Squares )[10]:

$$
S S T=\sum_{i=1}^{n}\left(y_{i}-\bar{y}\right)^{2}
$$


It reflects the size of the volatility of the data. Residual sum of squares is: $\operatorname{SST}=\sum_{i=1}^{n}\left(y_{i}-\hat{y}_{i}\right)^{2}$, From the above analysis, the properties in the secured interest really does a very important significance on it.

\section{Conclusion}

According to the traditional theory, the emergence and the setting of a secured interest are in order to strengthen the economic security of people 's day-to-day economic life, today, along with the further development of the social economy, especially the subsequent commodity economy mode shift, a secured interest that just meets the needs of the people and protects the debt existence no longer exists. So, in the future development, the secured interest must become the development trend of going towards independence, only the independent driving force can give debt trading a diversified development, secured interest will be able to have the liquidity in the secured interest and debt transactions. Therefore, the property of the secured rights will gradually fade, and the development of secured interest in China 's will become the main trend .

\section{References}

[1] Zhang Xiang. The property of the independent trend on a secured interest. Ocean University of China , 2012 (04):74-68.

[2] Deng Pingping, Yuan Liguang. Real rights for secured independence study. Journal of Xiangtan institute of technology ,2008(4):112-115.

[3] CaoYan, Liu Jun. Concerning the independence of the real rights for security. Journal of Xiangtan university, 2010 (11):11-15

[4] Mei Ruiqi. Concerning the relationship between the real rights for security independence and real right behavior. Wu Yinxing. Journal of Zhejiang industry and commerce university, 2010(5):88-92.

[5] Gong Shanshan. Concerning security right nature. Journal of Guangxi university, 2012 (6):3437

[6] Du Kong. Property law of real rights for security on the breakthrough of the guarantee law. Journal of Fudan university, 2009 (4):72-76.

[7] Tan Zilu. The theory of real rights for security .Journal of Jilin university, 2009(5):88-91.

[8] Sun Jiang. Theory of real rights for security function. Politics and law review, 2008(3): 3-5.

[9] Liao Huanguo, Xie Wei. Theory of the modern trend of the real rights for security .Social scientists, 2009(9):101-103.

[10] Min Chen.Lexis Nexis China 31st May Release Screen shot. China EPD, 2012(5):22-27 